\title{
Japanese Community Pharmacists' Practice Research Literacy
}

\author{
Yasuhiro Sawada1,2, Rieko Takehira1, Shigeo Yamamura ${ }^{*}$ \\ ${ }^{1}$ Faculty of Pharmaceutical Sciences, Josai International University, Chiba, Japan \\ ${ }^{2}$ Welcia Yakkyoku Co. Ltd., Tokyo, Japan \\ Email: ${ }^{*}$ s_yama@jiu.ac.jp
}

Received 18 August 2015; accepted 18 September 2015; published 21 September 2015

Copyright (C) 2015 by authors and Scientific Research Publishing Inc.

This work is licensed under the Creative Commons Attribution International License (CC BY).

http://creativecommons.org/licenses/by/4.0/

(c) (i) Open Access

\begin{abstract}
Objectives: Lack of basic practice research literacy could be considered a barrier to conducting or participating in practice research. Therefore, we examined pharmacy practice research literacy in Japanese community pharmacists. Methods: Community pharmacists $(n=478)$ who delivered presentations at three major pharmacy-related conferences in 2012 and 2013 completed the survey. We selected $10 \mathrm{key}$ terms related to practice research and asked participants whether they knew the meaning of. Questionnaires were sent to and returned by pharmacists via mail. Results: Of the 478 pharmacists who received questionnaires, 230 (47.9\%) completed the survey. The response rates indicating that participants were familiar with the 10 key terms were approximately $\mathbf{5 0 \%}$ or lower. The highest response rate was $67.0 \%$ for "bias", and the lowest was 17.0\% for "PICO/PECO: Patient-Intervention-Comparison-Outcome/Patient-Exposure-Comparison-Outcome”. Younger pharmacists tended to know several key terms, such as "p values”, “bias”, and “outcome”. Conclusion: Japanese community pharmacists were not knowledgeable with respect to conducting and participating in pharmacy practice research. Practice research knowledge was superior in younger pharmacists. Education in pharmacy schools and continuing professional development programs is important for community pharmacists' practice research development.
\end{abstract}

\section{Keywords}

Pharmacy Practice Research, Research Literacy, Japanese Community Pharmacists

\section{Introduction}

The community pharmacy profession, which was previously product focused, now involves patient-focused practice. There is a need to establish evidence-based practice to expand the field, as it is the only practice accepted ${ }^{*}$ Corresponding author. 
by other healthcare practitioners. In addition, consumers and patients have become more informed and demanding with respect to the services offered by pharmacists [1].

Pharmacy practice research topics, such as service provision, delivery, and development; pharmacists' professional activities; and service quality and safety, are widespread in the field of pharmaceutical service [2]. However, pharmacists are sometimes reluctant to conduct or participate in practice research [3].

There are some reviews of pharmacy practice research that intervention of community pharmacists can improve patient outcome research in blood pressure management, smoking cessation and chronic pain [4]-[6]. These researches became good evidence that community pharmacists can contribute to manage disease and promote healthcare system. However, the pharmacy practice research by Japanese community pharmacists has yet to be active [7].

We previously identified a number of barriers to conducting or participating in practice research and reported that Japanese community pharmacists were inactive in terms of practice research. The greatest barrier was a lack of time [7]. Other studies have also identified lack of time as pharmacists' main barrier to conducting or participating in practice research [1] [8] [9].

Armour et al. categorized barriers to participating in research as follows: mindset, communication, infrastructure (time, money, and staff), and skills and knowledge [1]. They also suggested that most Australian pharmacists lacked some of the skills and/or knowledge required to conduct research [1]. In addition, a shortage of knowledge related to practice research was found to be a hidden barrier to conducting or participating in practice research in Japanese community pharmacists.

We conducted a survey to determine whether Japanese community pharmacists were familiar with essential key terms related to practice research. We also explored the relationship between practice research activities and pharmacy education.

\section{Method}

This survey was carried out a part of “Japanese Community Pharmacists' Barriers to Conducting or Participating in Practice Research" [7]. Community pharmacists who had delivered presentations at three major pharmacy-related conferences (annual meetings of The Pharmaceutical Society of Japan [10], Japanese Society of Pharmaceutical Health Care and Sciences [11], and Japan Pharmaceutical Association [12]) in 2012 and 2013 were selected using the annual meetings' abstracts. Their addresses were identified according to the author's occupation, and community pharmacists $(\mathrm{n}=478)$ were selected to participate in the study.

We selected 10 key terms commonly used to structure clinical questions, establish study designs, and evaluate results in practice research. These key terms are fundamental terms to do practice research. It would be acceptable that without of knowledge of these terms, pharmacists would not conduct or participating in practice research. All participants provided informed consent to participate in the study; they were then asked whether they were familiar with each key term. Questionnaires were sent to and returned by pharmacists via mail.

The questionnaire included items concerning participants' age and sex, years of experience in their current employment, the type of research described in their presentations, and their familiarity with 10 key terms.

Statistical analysis was performed using JMP Version 11.0 (SAS Institute Japan). Chi-square was used to analysis whether proportions of "know" responses in each key term differ from one another variable. CochranArmitage test was used to assess a trend of proportions of "know" responses in each key term on age. The McNemar's test was used to assess the significance of the difference between two correlated proportions for dependent (paired) categorical data. The test can assess whether a proportion of "know" responses in one key term differ from a proportion of "know" responses in another key term. The significance level was set at 0.05 for all tests.

\section{Results}

Of the 478 pharmacists who received the questionnaire, 230 (47.9\%) completed the survey. Table 1 summarizes the community pharmacists' characteristics. Large proportions of pharmacists were in their 30s or 40s and had 5 - 20 years of practice experience. The majority of participants who conducted practice research had at least five years of practical experience. More than one third of participants' presentations introduced their daily practice, and many provided little evidence of their pharmacy practice research. Intervention studies, involving a higher 
Table 1. Community pharmacists’ characteristics.

\begin{tabular}{ll}
\hline Characteristics & Total N = 230 \\
\hline Sex n (\%), missing: 3 & $152(67.0)$ \\
Male & $75(33.0)$ \\
Female & \\
Age n (\%), missing: 1 & $27(11.8)$ \\
20 s & $93(40.6)$ \\
30 s & $54(23.6)$ \\
40 s & $39(17.0)$ \\
50 s & $16(7.0)$ \\
$>60$ s & \\
Years of practical experience n (\%), missing: 4 & $7(3.1)$ \\
$<2$ years & $33(14.6)$ \\
2 - 5 years & $74(32.7)$ \\
5 - 10 years & $70(31.0)$ \\
10 - 20 years & $42(18.6)$ \\
$>20$ years & $18(8.1)$ \\
Type of research n (\%), missing: 7 & $43(19.3)$ \\
Introduction of practice & $94(42.1)$ \\
Observation study & $68(30.5)$ \\
Intervention study & \\
\hline
\end{tabular}

evidence level, comprised only $8 \%$ of all presentations. Approximately $60 \%$ of presentations were presented using a poster.

Table 2 shows the numbers and proportions of pharmacists who recorded "know" responses for the key terms. Although all key terms were common in practice research, "know" response rates for the 10 key terms were approximately $50 \%$ or lower. The highest was $67.0 \%$ for "bias" and the lowest was $17.0 \%$ for "PICO/PECO: patient-Intervention-Comparison-Outcome/Patient-Exposure-Comparison-Outcome”. These results suggest that Japanese community pharmacists were not knowledgeable regarding practice research. However, terms used in statistics, such as "p value" and "95\% confidence interval" were well known, and those related to structuring clinical questions, such as "clinical question”, "research question", and "PICO/PECO” were less well known by Japanese community pharmacists.

Table 3 shows the effect of age on "know" response rates forthe10 key terms. Results of the Cochran-Armitage test showed that a higher number of younger pharmacists were familiar with " $p$ value" $(p=0.021)$ relative to that of senior pharmacists. In addition, although the differences were nonsignificant, a higher number of younger pharmacists were familiar with several key terms, such as "bias" ( $p=0.071)$ and "outcome" $(p=0.115)$, relative to that of senior pharmacists.

Table 4 shows the McNemar test p values for correlations between paired proportions of participants who were familiar with key terms. In these cases, if $p$ values were greater than 0.05 , the two proportions involved were considered dependent, suggesting that participants who were familiar with one term were also familiar with another. Pharmacists who were familiar with "clinical question" were also familiar with "research question" and "confounding". Pharmacists who were familiar with "reliability and validity" were also familiar with "observational and intervention study". In addition, pharmacists who were familiar with "p value" were also familiar with "95\% confidence interval". These results indicate that some pharmacists were knowledgeable about statistics and study design in practice research, while others were not. 
Table 2. Numbers and proportions of pharmacists who provided "know" responses.

\begin{tabular}{ll}
\hline Key terms & Number (\%) \\
\hline Clinical question & $59(25.7)$ \\
Research question & $56(24.3)$ \\
PICO/PECO & $39(17.0)$ \\
Outcome & $77(33.5)$ \\
Bias & $154(67.0)$ \\
Confounding & $54(23.5)$ \\
Reliability and validity & $94(40.9)$ \\
Observational study and intervention Study & $102(44.3)$ \\
p value & $127(55.2)$ \\
95\% confidence interval & $128(55.6)$ \\
\hline
\end{tabular}

Numbers (\%) out of 230 responses. PICO/PECO: patient-Intervention-Comparison-Outcome/Patient-ExposureComparison-Outcome).

Table 3. Change in pharmacists' "know" response rates for the 10 key terms according to age.

\begin{tabular}{llllllll}
\hline Key terms & $20 \mathrm{~s}(\mathrm{n}=27)$ & $30 \mathrm{~s}(\mathrm{n}=93)$ & $40 \mathrm{~s}(\mathrm{n}=54)$ & $50 \mathrm{~s}(\mathrm{n}=39)$ & $>60 \mathrm{~s}(\mathrm{n}=16)$ & $\mathrm{p}$ value $)^{1)}$ & $\mathrm{p} \mathrm{value}^{2)}$ \\
\hline Clinical question & $10(37.0)$ & $27(29.0)$ & $6(11.1)$ & $12(30.8)$ & $4(25.0)$ & 0.064 & 0.310 \\
Research question & $10(37.0)$ & $22(23.7)$ & $10(18.5)$ & $10(25.6)$ & $4(25.0)$ & 0.492 & 0.451 \\
PICO/PECO & $5(18.5)$ & $16(17.2)$ & $7(13.0)$ & $5(12.8)$ & $5(31.3)$ & 0.479 & 0.795 \\
Outcome & $45(44.4)$ & $36(38.7)$ & $13(24.1)$ & $10(25.6)$ & $6(37.5)$ & 0.205 & 0.115 \\
Bias & $22(81.5)$ & $65(70.0)$ & $33(61.1)$ & $22(56.4)$ & $11(68.8)$ & 0.219 & 0.071 \\
Confounding & $5(18.5)$ & $22(23.7)$ & $12(22.2)$ & $8(20.5)$ & $6(37.5)$ & 0.668 & 0.427 \\
Reliability and validity & $15(55.6)$ & $39(41.9)$ & $16(29.6)$ & $14(35.9)$ & $9(56.3)$ & 0.123 & 0.454 \\
$\begin{array}{l}\text { Observational study and } \\
\text { Intervention Study }\end{array}$ & $18(66.7)$ & $40(43.0)$ & $19(35.2)$ & $16(41.0)$ & $8(50.0)$ & 0.102 & 0.206 \\
$\begin{array}{l}\text { p value } \\
\text { 95\% Confidence interval }\end{array}$ & $17(63.0)$ & $57(61.3)$ & $30(55.6)$ & $14(35.9)$ & $8(50.0)$ & 0.088 & 0.021 \\
\hline
\end{tabular}

Numbers of "know" responses with rates in parentheses. ${ }^{1)}$ Chi-square test; ${ }^{2)}$ Cochran-Armitage test. PICO/PECO: Patient-Intervention-ComparisonOutcome/Patient-Exposure-Comparison-Outcome.

Table 4. McNemartest p values for correlations between paired proportions of participants familiar with key terms.

\begin{tabular}{|c|c|c|c|c|c|c|c|c|c|c|}
\hline Key Terms & (1) & (2) & (3) & (4) & (5) & (6) & (7) & (8) & (9) & (10) \\
\hline (1) Clinical question & 1.000 & 0.439 & 0.032 & 0.181 & $<0.001$ & 0.508 & $<0.001$ & $<0.001$ & $<0.001$ & $<0.001$ \\
\hline (2) Research question & & 1.000 & 0.010 & 0.004 & $<0.001$ & 0.793 & $<0.001$ & $<0.001$ & $<0.001$ & $<0.001$ \\
\hline (3) PICO/PECO & & & 1.000 & $<0.001$ & $<0.001$ & 0.025 & $<0.001$ & $<0.001$ & $<0.001$ & $<0.001$ \\
\hline (4) Outcome & & & & 1.000 & $<0.001$ & 0.002 & 0.024 & 0.003 & $<0.001$ & $<0.001$ \\
\hline (5) Bias & & & & & 1.000 & $<0.001$ & $<0.001$ & $<0.001$ & 0.001 & 0.001 \\
\hline (6) Confounding & & & & & & 1.000 & $<0.001$ & $<0.001$ & $<0.001$ & $<0.001$ \\
\hline (7) Reliability and validity & & & & & & & 1.000 & 0.317 & $<0.001$ & $<0.001$ \\
\hline $\begin{array}{l}\text { (8) Observational study and } \\
\text { intervention study }\end{array}$ & & & & & & & & 1.000 & 0.002 & 0.001 \\
\hline (9) p value & & & & & & & & & 1.000 & 0.858 \\
\hline (10) $95 \%$ Confidence interval & & & & & & & & & & 1.000 \\
\hline
\end{tabular}

The numbers in parentheses in the column headings represent the key terms in the far-left column. PICO/PECO: Patient-Intervention-ComparisonOutcome/Patient-Exposure-Comparison-Outcome. 


\section{Discussion}

With the change in community pharmacy from a product-focused to a patient-focused profession, Japanese community pharmacists should ensure that their professional roles improve patients' outcomes via practice research. In our previous study, we identified Japanese community pharmacists' barriers to conducting or participating in practice research. The greatest barrier was lack of time to conduct research presumably due to the amount of time spent dispensing medication and counseling patients [7].

We also sought to determine whether education was a hidden barrier to conducting or participating in practice research in Japanese community pharmacists. If pharmacists are knowledgeable about practice research, they should be familiar with as know the meanings of essential key terms used in pharmacy practice research. We asked pharmacists whether they were familiar with10 key terms, to explore their practice research literacy.

The "know" response rates for key terms used to identify practice-related problems, such as "clinical question", "research question", and "PICO/PECO" were low at $<30 \%$. As the ability to identify clinical and research questions is essential in establishing practice research, Japanese community pharmacists would not have sufficient knowledge to conduct intervention studies. Therefore, intervention studies, which require a higher level of evidence, constituted only $8 \%$ of all presentations. This suggests that Japanese community pharmacists would find intervention studies difficult to conduct.

Many pharmacists were unfamiliar with other key terms relating study design and the evaluation of data, suggesting that they would not be knowledgeable about practice research. Some of the pharmacists in this survey exhibited a stronger interest in research relative to that shown by others, who also appeared to be less knowledgeable about practice research.

When we analyzed the relationship between a proportion of "know" responses for each key term and characteristics of pharmacists, there were statistically no significant relations except for age. Younger pharmacists tended to know that "p value" was related to statistics. In addition, pharmacists in their 20s appeared to have superior knowledge of several key terms relative to that of pharmacists of other ages (statistically nonsignificant). These findings could result in a change in Japanese pharmacy education. In Japan, 6-year pharmacy education programs were introduced in 2006 to improve pharmacy students' clinical skills [13]. The introduction of subject-related research in many pharmacy schools has provided young pharmacists with the opportunity to learn about practice and basic research. The difference of educational level of pharmacists would be other cause of the result. However we did not have the data to assess educational level of pharmacist in this survey.

In recent research, research experience prior to residency training strongly predicted subsequent practice research publication [14]. This report indicated that practice research training for entry-level pharmacists would be important for them to conduct and participating in practice research. Many Japanese community pharmacists did not receive practice research training when they were in pharmacy school. These results suggest that the development of educational programs concerning pharmacy practice research is important in both pharmacy schools and continuing professional development, to develop practice research for community pharmacists. Experienced pharmacists and faculty members should support less experienced pharmacists in conducting their practice research.

In Japan, if they learned how to conduct or participating in pharmacy practice research in pharmacy school, practice research by community pharmacists would give evidence that pharmacists can improve patient outcome.

\section{Limitations}

"Know" responses, which offered an indication as to whether participants were familiar with the key terms, were provided via self-evaluation. The questionnaire may not have accounted for potential differences in levels of understanding and familiarity with key terms between pharmacists. Therefore, the results of the survey represent pharmacists' literacy on a superficial level. In addition, pharmacists who participated in the survey demonstrated a strong interest in research. Therefore, the results of the survey could have overestimated Japanese community pharmacists' knowledge of practice research.

\section{Conclusion}

Japanese community pharmacists were not knowledgeable about conducting or participating in pharmacy practice research. Younger pharmacists demonstrated superior knowledge of practice research. Education in phar- 
macy schools and continuing professional development programs is important in community pharmacists' development of practice research. Support by university stuffs to develop practice research in Japan would be necessary.

\section{Conflict of Interest}

This research was supported by the OTC Self-Medication Promotion Foundation.

\section{Acknowledgements}

We would like to express our thanks to Ms. R. Hirokawa, A. Hirano, and M. Fujii for their technical assistance.

\section{References}

[1] Armour, C., Brillant, M. and Krass, I. (2007) Pharmacists' Views on Involvement in Pharmacy Practice Research: Strategies for Facilitating Participation. Pharmacy Practice, 5, 59-66.

http://dx.doi.org/10.4321/S1886-36552007000200002

[2] Smith, F.J. (2010) Conducting Your Pharmacy Practice Research Project: A Step-by-Step Guide. 2nd Edition, Pharmaceutical Press, London.

[3] Hébert, J., Laliberté, M.C., Berbiche, D., Martin, E. and Lalonde, L. (2013) The Willingness of Community Pharmacists to Participate in a Practice-Based Research Network. Canadian Pharmacists Journal, 146, 47-54. http://dx.doi.org/10.1177/1715163512473240

[4] Santschi, V., Chiolero, A., Colosimo, A.L., Platt, R.W., Taffé, P., Burnier, M., Burnand, B. and Paradis, G. (2014) Improving Blood Pressure Control through Pharmacist Interventions: A Meta-Analysis of Randomized Controlled Trials. Journal of the American Heart Association, 3, e000718. http://jaha.ahajournals.org/content/3/2/e000718.full http://dx.doi.org/10.1161/JAHA.113.000718

[5] Saba, M., Diep, J., Saini, B. and Dhippayom, T. (2014) Meta-Analysis of the Effectiveness of Smoking Cessation Interventions in Community Pharmacy. Journal of Clinical Pharmacy and Therapeutics, 39, 240-247. http://dx.doi.org/10.1111/jcpt.12131

[6] Bennett, M.I., Bagnall, A.M., Raine, G., Closs, S.J., Blenkinsopp, A., Dickman, A. and Ellershaw, J. (2011) Educational Interventions by Pharmacists to Patients with Chronic Pain: Systematic Review and Meta-Analysis. Clinical Journal of Pain, 27, 623-630. http://dx.doi.org/10.1097/AJP.0b013e31821b6be4

[7] Sawada, Y., Takehira, R. and Yamamura S. (2015) What's the Barrier to Conduct or Participate in a Practice Research in Japanese Community Pharmacists. Pharmacology and Pharmacy, 6.

[8] Schommer, J.C. (2010) Establishing Pharmacist Practice-Based Research Networks. APhA Foundation White Paper. Washington (DC): American Pharmacists Association. http://www.aphafoundation.org/sites/default/files/ckeditor/files/PBRNet\%20White\%20Paper\%20for\%20APhA\%20Fo undation\%20Final\%20-\%20May\%2027\%202010.pdf

[9] Simpson, S.H., Johnson, J.A., Biggs, C., Biggs, R.S., Kuntz, A., Semchuk, W., Taylor, J.G., Farris, K.B. and Tsuyuki, R.T. (2001) Practice-Based Research: Lessons from Community Pharmacist Participants. Pharmacotherapy, 21, 731739. http://dx.doi.org/10.1592/phco.21.7.731.34570

[10] The Pharmaceutical Society of Japan. http://www.pharm.or.jp/index_e.html

[11] Japanese Society of Pharmaceutical Health Care and Sciences. (Japanese) http://www.jsphcs.jp/index.php

[12] Japan Pharmaceutical Association. http://www.nichiyaku.or.jp/e/default.html

[13] Annual Report of the Japan Pharmaceutical Association 2014-2015. http://www.nichiyaku.or.jp/e/data/anuual_report2014e.pdf

[14] Pinelli, N.R., Sikora, A.N., Witherspoon, L.A., Rao, K.V. and Rhoney, D.H. (2015) Impact of Pharmacy Residency Research Training on Residents' Actual Versus Perceived Ability and Interest to Identify and Solve Practice-Related Problems. Journal of Pharmacy Practice, in press. 